ISSN 1518-3483

Licenciado sob uma Licença Creative Commons

\title{
Mestrado profissional e mestrado acadêmico: aproximações e diferenças
}

\author{
Professional and Academic Master Courses: \\ approximations and differences
}

Master Profesional y Master Académico: aproximaciónes y diferencias

Marli Eliza Dalmazo Afonso de Andre*

Pontifícia Universidade Católica de São Paulo, São Paulo, Brasil

\section{Resumo}

O texto discute uma proposta de formação de profissionais da educação básica. Toma como pano de fundo alguns desafios enfrentados na formação dos mestrandos que buscam o Programa de Mestrado Profissional em Educação: Formação de Formadores, da PUC SP. O intuito do curso é criar condições para o desenvolvimento de sujeitos críticos, reflexivos, analistas simbólicos da realidade e implementadores de mudanças que concorram para uma educação de qualidade destinada às crianças e jovens da escola básica. A proposta curricular está centrada em disciplinas e atividades que visam articular a

* MEDAA: Doutorado em Psicologia da Educação, e-mail: marliandre@pucsp.br 
pesquisa e a prática pedagógica, o que provocou, por parte dos professores do programa, um questionamento sobre o que caracteriza a pesquisa no mestrado profissional e em que medida se distingue da pesquisa no mestrado acadêmico. Vários autores estrangeiros, como Stenhouse, Elliot, Tripp, Lerner que discutem a pesquisa e a intervenção na escola e na sala de aula foram revisitados. Propostas de autores brasileiros como Lüdke e Gatti também foram retomadas para ajudar a esclarecer as dúvidas. Constatou-se que a diferenças fundamental encontra-se no objeto de estudo, um tem como referência a prática profissional, o outro, o avanço do conhecimento. O ponto de aproximação entre a pesquisa acadêmica e a pesquisa da prática é o rigor teórico-metodológico: ambas exigem planejamento, controle e sistematização do conhecimento.

Palavras-chave: Mestrado profissional. Formação. Educação básica. Pesquisa da prática pedagógica.

\begin{abstract}
The paper discusses a proposal for professional training of basic educators. It takes as a background some challenges faced in the education of graduate students following a Professional Master's Program in Education: Education of Teacher Educators in the Catholic University of Saint Paul. The course objective is to create conditions for the development of critical, reflective, symbolic analysts of reality and change makers that can contribute to a good education to children and youth in basic school. The proposed curriculum focuses on courses and activities intended to connect research and pedagogical practice, which led to a question: what characterizes research in the professional master's degree and to what extent it is different from research in academic master. Several foreign authors, such as Stenhouse, Elliot, Tripp, Lerner who discuss research and intervention at school and in the classroom were revisited. Brazilian authors such as Lüdke and Gatti were also reviewed to help answer the question. It was found that the main difference lies in the focus of the study: in one the reference is the professional practice, in the other the focus is in the advancement of knowledge. The common point between academic and practice research is theoretical and methodological rigor: both require planning, control and knowledge systematization.
\end{abstract}


Keywords: Professional Master. Education trainning. Basic education. Research on Pedagogic Practice.

\section{Resumen}

El artículo discute una propuesta para la formación profesional de educadores de la educación básica. Se toma como un fondo algunos retos en la formación de los estudiantes de postgrado que buscan el Master Profesional en Educación: Formación de formadores, en Ia PUC SP. El objetivo del programa es crear condiciones para el desarrollo de profesionales críticos, reflexivos, analistas simbólicos de la realidad y ejecutores de los cambios que contribuyen a una educación de calidad a los niños y jóvenes de educación básica. El plan de estudios propuesto se centra en cursos y actividades dirigidas a la articulación entre investigación y la práctica pedagógica, lo que llevó, los profesores del programa, a una cuestión sobre el que caracteriza la investigación en el máster profesional y en qué medida se distingue de la investigación en el master académico. Varios autores extranjeros, como Stenhouse, Elliot, Tripp, Lerner que discuten la investigación y la intervención en la escuela y en el aula fueron revisados. Las propuestas de los autores brasileños como Lüdke y Gatti también se incorporaron a ayudar a responder la pregunta. Se encontró que la diferencia fundamental radica en el objeto de estudio, uno tiene como referencia la práctica profesional, el otro el avanzo del conocimiento. El punto de aproximación entre la investigación académica y la práctica es el rigor teórico y metodológico: ambos requieren planificación, control y sistematización del conocimiento.

Palabras clave: Master profesional. Formación. educación básica. Investigación práctica.

\section{Introdução}

Quais as aproximações e diferenças entre o mestrado profissional e o mestrado acadêmico? Esse é o ponto de partida das considerações e proposições que faço neste texto. Como a pós-graduação stricto sensu já tem uma longa trajetória no Brasil, centrada nos programas de cunho 
acadêmico, e como os mestrados profissionais são bastante recentes, é quase natural que haja indagações sobre os pontos que os diferenciam ou os aproximam.

A área de educação relutou muito para aceitar a implantação dos mestrados profissionais no Brasil, baseada em justificativas razoáveis, uma das quais o temor de perda de valorização da pesquisa, espaço conquistado com muito esforço. Assim, por tratar-se de uma iniciativa bastante recente - o primeiro mestrado profissional em educação foi aprovado pela CAPES em 2009 - torna-se oportuno discutir as diferenças e similitudes entre o mestrado profissional e o acadêmico.

Tenho interesse direto nessas questões pelo fato de ter participado da equipe que formulou uma proposta de Mestrado Profissional em Educação, na PUCSP. Com recomendação da CAPEs, o Programa iniciou as atividades acadêmicas no segundo semestre de 2013, sob minha coordenação. O Programa, que tem o foco na formação de formadores de professores da educação básica, está organizado em disciplinas e atividades, que objetivam propiciar aos pós-graduandos oportunidade de reflexão crítica sobre sua prática profissional e de investigação sobre seu trabalho.

Quem são os mestrandos que buscam esse curso? A grande maioria atua na rede pública de ensino e uma minoria em Organizações não Governamentais (ONG) ou no Sistema S (SESI, SENAC). A maior parte desses alunos exerce função de coordenação pedagógica, direção de escola ou supervisão escolar, e uma parte pequena está em sala de aula. Atentos a esse público majoritariamente composto por práticos, nosso intuito foi criar condições para que se desenvolvessem profissionalmente, como sujeitos críticos, reflexivos e implementadores de mudanças que concorram para uma educação de qualidade destinada às crianças e jovens da educação básica.

Para concretizar essa proposta, concluímos que a formação desses profissionais deveria estar centrada na articulação entre pesquisa e prática pedagógica. Essa convicção provocou alguns questionamentos e desafios a serem enfrentados pela equipe de docentes do curso, a maioria com muita experiência nos programas acadêmicos de mestrado 
e doutorado. Tínhamos consciência de que nosso trabalho no Mestrado Profissional não poderia repetir o que fazíamos no mestrado acadêmico, teríamos que aprender a fazer de um outro jeito.

Uma questão básica era a seguinte: como estruturar o Programa de modo a contemplar a articulação entre pesquisa e prática? Subjacente a essa, estava a dúvida maior: o que distingue o mestrado profissional do acadêmico? E, associada a essa, havia outra questão bem específica: em que consiste o trabalho final de conclusão do mestrado profissional?

A leitura de alguns textos, especialmente os de Ribeiro (2005, 2006) ajudaram a entender a especificidade do Mestrado Profissional (MP). Em um desses textos, Ribeiro (2005, p. 10) explica que as justificativas para criação do MP pela CAPES, foram, por um lado a exigência da sociedade atual para ter uma formação qualificada, mesmo para os setores que não atuam na docência universitária ou não se envolvem em pesquisa de ponta; e por outro lado, a constatação de que muitos mestres e doutores buscam um destino profissional fora do ensino superior, o que evidencia que há demanda de trabalho para o pessoal qualificado. Ao se referir à diferença entre o mestrado profissional (MP) e o acadêmico (MA), Ribeiro (2005, p. 15) indica o produto, ou o resultado do curso. Em suas palavras: "No MA pretende-se pela imersão na pesquisa, formar, a longo prazo um pesquisador". Já no MP, segundo o autor, também deve ocorrer a imersão na pesquisa, mas o objetivo é formar alguém que "saiba localizar, reconhecer, identificar e sobretudo, utilizar a pesquisa de modo a agregar valor a sua atividade". Estaria ele advogando ao pós-graduando do MP o papel de mero consumidor de pesquisa?

Em texto escrito posteriormente, Ribeiro (2006, p. 214) esclarece um pouco mais seu ponto de vista sobre o lugar da pesquisa no MP: "espera-se que a pessoa, mesmo não pretendendo depois ser um pesquisador, incorpore certos valores e certas práticas com a pesquisa, que façam dele, em definitivo, um usuário privilegiado da pesquisa”. Especifica um pouco melhor sua proposta, ao dizer que 
O que se almeja é algo aparentemente simples, mas bastante ambicioso e difícil, que o aluno entenda a importância da pesquisa em sua área profissional, que saiba onde encontrar a pesquisa ainda não feita, mas que se fará no futuro - e finalmente, que seja capaz de incorporá-la em seu exercício da profissão (RIBEIRO, 2006, p. 215).

Concordo plenamente com a proposta de Ribeiro (2005, 2006) quanto ao destaque que deve ter a pesquisa no $\mathrm{MP}$, mas acrescento que seu lugar na formação do profissional é também o de propiciar ferramentas que lhe permitam compreender e analisar criticamente a sua prática profissional e encontrar caminhos para aperfeiçoá-la. Defendo a proposta de formar o pesquisador prático.

Para isso, julgo necessário explicitar melhor essa proposta. No meu ponto de vista, a pesquisa visa a constituição de sujeitos autônomos, que desenvolvam opiniões e ideias próprias, que ao fazer uma leitura crítica da realidade, saibam o que e onde buscar referências e recursos, para entender o que se passa, e para delinear caminhos de atuação nessa realidade.

Neste sentido, minha proposta avança um pouco mais do que a de Ribeiro, pois considero que ser um consumidor ou usuário privilegiado de pesquisa é muito pouco, não basta ao mestrando reconhecer a importância da pesquisa, saber localizá-la e usá-la em sua prática. É preciso que o mestrando desenvolva uma disposição para a pesquisa, o que vai exigir dele a aquisição de atitudes e habilidades, tais como, problematizar a realidade, buscar dados e referências para elucidar as questões que o intrigam, saber tratar os dados e referências localizados e expressar seus achados. Isso vai implicar o aprendizado da problematização, da argumentação, da revisão bibliográfica, da produção e análise de dados, assim como a sistematização e o relato do caminho percorrido.

Trazendo essa proposta para o Programa de Mestrado Profissional em Educação: formação de formadores, tentamos nos estruturar dentro da seguinte lógica: se nosso público é constituído por profissionais práticos, temos que montar uma estrutura curricular que 
contemple disciplinas e atividades centradas na reflexão crítica da prática profissional e no delineamento de caminhos para aperfeiçoá-la.

Desenvolvimento profissional do formador e intervenções avaliativas foram as duas linhas de pesquisa, em torno das quais foram criadas as disciplinas e atividades complementares.

Se conseguimos certa clareza sobre nossos propósitos com o curso e sobre como estruturá-lo, ficamos com muitas dúvidas sobre o trabalho final. Afinal qual a diferença entre uma dissertação de mestrado e o trabalho final do mestrado profissional?

$\mathrm{Na}$ busca dos esclarecimentos, recorreu-se primeiramente à Portaria 80/98 da CAPES (BRASIL, 1999) que dispõe sobre o reconhecimento dos mestrados profissionais, onde se verificou que são muitos os tipos de trabalho final que podem ser escolhidos, ficando os programas com a liberdade de definir aquelas alternativas que melhor atendam seus propósitos e sua realidade. $\mathrm{O}$ item d) do artigo $2^{\circ}$ da referida Portaria (BRASIL, 1999) estabelece o que é esperado do pós-graduando na conclusão do mestrado profissional: "que demonstre domínio do objeto de estudo, (sob a forma de dissertação, projeto, análise de casos, performance, produção artística, desenvolvimento de instrumentos, equipamentos, protótipos, entre outras, de acordo com a natureza da área e os fins do curso) e capacidade de expressar-se lucidamente sobre ele”. São muitas possibilidades, algumas muito próximas do mestrado acadêmico, como a dissertação.

Então, foi necessário buscar autores que nos ajudassem a entender melhor a questão da pesquisa do profissional prático e outros conceitos correlatos como: professor pesquisador, prático reflexivo, pesquisa-ação, pesquisa do prático e outros. Assim, revisitamos textos de autores como: Stenhouse, Elliot, Zeichner, Tripp, Lüdke, Lerner e Gatti e procuramos ouvir colegas de outros mestrados profissionais em educação que partilhavam conosco das mesmas dúvidas.

Stenhouse (1968) foi uma de minhas primeiras referências sobre o tema do professor pesquisador, quando ainda fazia o doutorado no 
final dos anos 1970. Em pleno domínio do tecnicismo na área de educação, conheci as ideias de Stenhouse, que fazia parte de um movimento inovador, cujos proponentes, estudiosos das questões curriculares, defendiam uma visão do professor não como um técnico que aplica programas e inovações desenhadas por especialistas, mas como produtor de conhecimentos, um profissional que reflete sobre sua prática e faz mudanças em sua ação, com base nessas reflexões. O conhecimento, nesta perspectiva, era visto não como algo definitivo, fechado, mas como provisório e aberto a questionamentos e discussões.

As ideias de Stenhouse foram e continuam sendo desenvolvidas por Elliot $(1978,2009)$, que critica o modo como, ao longo do tempo, a proposta de Stenhouse foi sendo descaracterizada no Reino Unido, perdendo aquele sentido de que o currículo deve ser um processo construído colaborativamente entre professores da escola e os pesquisadores da universidade, passando a assumir um caráter positivista, que valoriza apenas o produto da ação, em uma lógica de racionalidade instrumental. Elliot (2009) propõe a "Lesson Study", que, segundo ele, guarda muitos pontos em comum com a proposta do "ensino baseado na pesquisa" de Stenhouse. Ambas partem dos problemas concretos do ensino, enfatizam a ligação entre teoria e prática, a colaboração não apenas entre professores, mas também entre os pesquisadores da universidade e os professores da escola, a aproximação entre o universo acadêmico e o ensino nas escolas. A "Lesson Study" consiste em uma aula planejada coletivamente, obedecendo a um ciclo de ação e reflexão; os professores fazem um plano conjunto, um deles põe em prática, os outros observam, em seguida discutem as observações, fazem as reformulações necessárias para que outro colega coloque em prática e assim sucessivamente.

Outro autor que trouxe uma ótima contribuição para nossas discussões foi Zeichner (1993), que propõe a pesquisa ação "socialmente crítica" a ser realizada em múltiplos níveis como na sala de aula, na escola e na sociedade, para contribuir com a justiça social, cultural, política e econômica. Em um texto recente (ZEICHNER, s.d.) ele defende que a 
pesquisa ação na formação inicial possa servir de apoio à luta de maior justiça social em um mundo tão injusto e desumano.

Muito valiosas também foram as contribuições de David Tripp (2005, p. 443) que além de situar historicamente a pesquisa-ação e seus inúmeros desdobramentos, oferece uma definição bem simples e clara. A pesquisa-ação nas palavras do autor é "toda tentativa sistemática e empiricamente fundamentada de aprimorar a prática”. Ele discute ainda o papel da teoria na pesquisa-ação, o ciclo de desenvolvimento de um trabalho dessa natureza e questões relativas aos procedimentos metodológicos, tais como: a necessidade de controle e sistematização do conhecimento, o papel da reflexão, os cuidados com a participação e a ética.

A investigação didática da pesquisadora argentina Délia Lerner (2009) foi outra fonte consultada. A autora discute a diferença entre pesquisa acadêmica e investigação didática, ressalta que ambas têm como ponto comum a preocupação com o rigor e como principal diferença, o objeto de estudo. Em suas explicações, a investigação didática é um tipo de pesquisa como a etnográfica, a psicológica, a sociológica e busca produzir conhecimento acerca das relações entre ensino e aprendizagem de conteúdos específicos. Acrescenta ainda que a pesquisa deve ter um caráter formativo no curso de formação inicial, de modo a levar os futuros professores a desnaturalizarem conteúdos e práticas vividas como alunos, a conhecerem resultados de pesquisas, a terem acesso a conhecimentos didáticos e educativos em geral e posicionarem-se como estudantes permanentes.

Afora esses e muitos outros autores estrangeiros, temos no Brasil uma boa produção sobre a pesquisa do professor. Em seu livro $O$ Professor e a Pesquisa, Lüdke (2001) analisa as proposições de muitos autores que escrevem sobre pesquisa ação, pesquisa do professor ou pesquisa do prático e nos alerta que tanto a pesquisa do professor quanto a pesquisa acadêmica requerem condições especiais - tempo, material, espaço, auxílio técnico - e rigor na sua condução.

Entre essas várias leituras, a contribuição mais direta e incisiva foi a de Gatti (2014) que fez uma apresentação no I Fórum de Mestrados 
Profissionais em Educação (FOMPE), realizado na Universidade Estadual da Bahis (UNEB), em março de 2014, sobre as diferenças entre Mestrado Acadêmico e Profissional. Neste Fórum, que contou com a presença de coordenadores de mais de 20 programas de MP em educação, ficou muito evidente a necessidade de explicitar o que se espera de um trabalho final de conclusão do Mestrado Profissional.

Para Gatti (2014), os Mestrados Profissionais devem ter o foco "nas dinâmicas relacionais de trabalho nas organizações educacionais e seus consequentes", além disso, devem mobilizar conhecimentos que permitam melhor qualificação do trabalho. Os tipos de trabalhos de conclusão sugeridos por ela são: a) pesquisas descritivo-diagnósticas de realidades situadas, visando proposições; b) criação, planejamento ou experimentação de propostas - de metodologias, de ações pedagógicas, de gestão, de softwares, de materiais didáticos; c) estudos avaliativos em pequena escala, com proposições.

Gatti fez, ainda, a distinção entre pesquisa acadêmica e pesquisa aplicada, esta última, denominada por ela de "pesquisa engajada". A pesquisa acadêmica tem a teoria como ponto de partida e de chegada e a problematização é construída com base na teoria ou em referentes teóricos, explica ela. O propósito da pesquisa acadêmica é "evidenciar realidades a partir de uma perspectiva teórica dada, validar teorias, criar novo ramo explicativo, levantar lacunas na teoria, propor outra ótica explicativa". Já a pesquisa "engajada" tem a realidade empírica como ponto de partida e de chegada e visa "evidenciar fatos específicos, pela compreensão de situações localizadas, buscando soluções e propondo alternativas”. A autora conclui que ambas exigem cuidados metodológicos, assim como modalidades e meios de investigação apropriados.

Os esclarecimentos de Gatti foram muito úteis, pois se confirmava a hipótese de que a diferença entre o MP e o MA estava no objeto. No entanto, restava um segundo desafio: como formar o pesquisador prático? Como estruturar uma disciplina que fornecesse as ferramentas para a constituição do pesquisador prático? 
Minha experiência como professora de metodologia da pesquisa e orientadora na pós-graduação durante quase 40 anos, ao mesmo tempo me inspirou e me provocou na definição de quais seriam os conteúdos e metodologias de um curso voltado à formação do pesquisador prático. Ponderei a mim mesma que a questão não estaria apenas no que, nos conteúdos, mas muito mais no como desenvolver os conteúdos. Inspirada nos autores revistos, concluí que o fundamental era manter um diálogo constante com o grupo de pós-graduandos, fomentando a discussão coletiva dos textos e autores lidos, mas ao mesmo tempo fazendo com que identificassem problemas vividos em sua prática profissional, registrassem esses problemas e discutissem, no coletivo grupal, quais os caminhos para elucidá-los. Era necessária a produção individual, mas não podia deixar de promover a discussão coletiva dessas produções. Precisava respeitar o tempo e o ritmo de cada um, ao mesmo tempo em que estimulava o avanço do grupo.

Essas decisões foram baseadas na convicção de que a pesquisa tem um importante papel na formação de sujeitos críticos e autônomos, pois lhes dá oportunidade de desenvolver ideias próprias, e de refletir sobre a prática profissional, identificando o que pode ser reforçado ou melhorado, de modo a contribuir com o processo de emancipação das pessoas. Como nos ensina Imbernón (2002, p. 27) “O objetivo da educação é ajudar a tornar as pessoas mais livres, menos dependentes do poder econômico, político e social". A pesquisa, quando voltada para a reflexão crítica da prática e para seu aprimoramento, com o objetivo último de promover a educação de crianças e jovens, pode desempenhar esse papel emancipatório defendido por Imbernón.

Os princípios que eu já havia definido em outro texto (ANDRÉ, 2012) ao discutir a formação inicial do professor pesquisador foram retomados, pois defendem o envolvimento ativo do sujeito-professor no processo de apropriação de conhecimentos, assim como a aprendizagem no coletivo, com a mediação do professor/supervisor.

Apoiada nesses princípios, propus uma metodologia (ANDRÉ, 2012, p. 124-126), em que ressalto a necessidade de desenvolver, com 
os futuros professores, não só uma atitude de pesquisador, mas também habilidades necessárias à realização de uma pesquisa, tais como: ter como ponto de partida uma problemática, o que vai requerer a aprendizagem da problematização; aprender a localizar fontes de consulta e a selecioná-las; a formular questões orientadoras; a conhecer procedimentos metodológicos como observação, entrevista, análise documental, registro de áudio e vídeo; a construir instrumentos de coleta de dados; a analisar dados e relatar a pesquisa. Apoiada nesses princípios, planejei e desenvolvi uma disciplina para os mestrandos, com uma sequência de tópicas, que será descrita a seguir.

1) Do tema ao problema de pesquisa - nesta unidade temática utilizo um recurso que tem se mostrado muito positivo: peço aos alunos que façam um registro reflexivo com o seguinte título: Minha relação com o tema da pesquisa. Oriento para que indiquem as origens do problema, respondendo às seguintes questões: Quem sou eu? De onde vem meu interesse de pesquisa? Quais aspectos da realidade profissional me incomodam? O que quero descobrir? É preciso que cada um encontre em sua história de vida e em sua trajetória profissional, algo que o mobilize, que o instigue a querer compreender, a saber mais.

Tive que ajudá-los a manter um equilíbrio entre querer contar a história de vida desde o dia do nascimento e escolher, na sua trajetória pessoal e profissional, aspectos relevantes para a definição do foco de estudo. Li os textos de cada um e os devolvi com apreciações. Pedi que, se necessário, reescrevessem e me devolvessem para nova apreciação, e assim continuamente. Ainda nessa fase, defrontei-me com o seguinte desafio: como ensinar o aluno a problematizar a realidade? Como ensiná-los a argumentar?

Para essa difícil tarefa, parece-me fundamental que os pós-graduandos leiam, leiam muito, tanto artigos e relatos de pesquisas, como livros, capítulos de livros, resenhas, revisões de literatura, e que consultem bancos de dados. Como diz Kaufmann (2011, p. 63), "Não existe pesquisa sem leitura. Pois nenhum tema é radicalmente novo e nenhum 
pesquisador pode pretender avançar sem o capital dos conhecimentos adquiridos em determinada área".

Problematizar requer muita leitura, tanto para conhecer o que já foi produzido sobre o tema, mas também para encontrar subsídios à formulação de objetivos, à construção de hipóteses teóricas e às análises do material coletado.

2) Revisão da Literatura - É preciso fazer um levantamento do estado do conhecimento a respeito do tema escolhido para que o pesquisador não repita o que já foi produzido. Ao desenvolver esse tópico enfrentei certa resistência. Alguns alunos diziam: "Ah, professora, não encontrei nada sobre meu tema!" Outros contestavam: "mas precisa mesmo levantar os estudos correlatos?" "Quantos?" "Começando em que ano?" Pareceu-me que por serem profissionais muito envolvidos com a prática, que é atraente e absorvente, não estavam muito convencidos da importância da leitura para fazer avançar sua prática. E foi preciso ensinar a ler, começando por: aprender a localizar fontes, saber selecionar, definir o banco de dados a ser consultado; depois: aprender a registrar, fazer fichamentos, organizar os dados; e ainda: como apresentar um texto, relacionando as fontes consultadas, mostrando pontos comuns e diferenças entre elas, localizando aspectos ainda não esclarecidos. Uma boa ajuda nessa tarefa é pedir que identifiquem quais são suas palavras-chave e a partir delas, façam o levantamento bibliográfico. Esse exercício deve culminar na produção de um texto que minimamente articule os estudos revistos. Cabe ao professor/orientador fazer a leitura crítica desses textos, devolve-los com as devidas observações, propor a apresentação e discussão em pequenos e grandes grupos.

3) A Formulação do Problema da Pesquisa - Feitas as leituras iniciais, que não abrangem só as pesquisas correlatas, mas também autores e conceitos relacionados ao tema, o pós-graduando pode retomar a tarefa de formulação do problema de pesquisa. Se ele fez um mapeamento 
do que já foi pesquisado sobre o assunto, pode identificar as lacunas do conhecimento, argumentar em que medida seu estudo tem algo a acrescentar, indicar sua relevância. Se já encontrou autores que trataram do tema escolhido, pode utilizá-los como referência para fortalecer seus pontos de vista e para mostrar quais os aspectos que ainda precisam de maior elucidação. Deve nascer daí a formulação do problema que não pode ser confundido com uma pergunta. Como diz Saviani (2009, p. 21), ter uma questão não significa ter uma situação problemática, pois não é a questão que caracteriza um problema, nem mesmo quando se desconhece a resposta, o problema existe quando se ignora uma coisa que se necessita saber, assim como uma dúvida que precisa ser esclarecida, uma dificuldade que precisa ser superada.

4) A definição dos objetivos - Costuma-se dizer que uma vez definido o problema, a pesquisa está bem encaminhada. Sim, porque do problema são derivados os objetivos a serem alcançados e apontado o caminho metodológico da pesquisa. Redigir objetivos, porém, não é tarefa fácil. Eles devem reproduzir a problemática de pesquisa em forma de linhas de ação, de metas a alcançar. A especificação dos objetivos gerais e específicos dá origem a várias dúvidas: Que verbos utilizar? Escrevo sob forma de perguntas ou não? Quantos objetivos é o ideal? São perguntas que não têm resposta simples, as orientações vão depender do problema, do conhecimento disponível, do âmbito de abrangência da pesquisa. Uma estratégia muito positiva é socializar esse exercício no coletivo, discutir os objetivos elaborados com os colegas, ouvir sugestões e críticas.

5) Conhecendo os Tipos de Pesquisa - Essa é uma unidade didática com objetivos mais informativos: fazer com que os mestrandos conheçam os fundamentos das abordagens qualitativas e vários tipos de pesquisa, tais como: os estudos autobiográficos, os estudos documentais, o estudo do tipo etnográfico, o estudo de caso, o survey, a pesquisa-ação e suas várias modalidades, incluindo a pesquisa ação colaborativa. 
Trazer convidados para expor suas pesquisas tem sido uma prática muito bem recebida e elogiada pelos pós-graduandos. Para escolher os convidados, tentamos associar o conhecimento de uma nova metodologia com o tema relacionado à prática pedagógica.

6) Procedimentos de Coleta de Dados - esse tópico é abordado por meio de oficinas, seminários, exercícios práticos. As temáticas são: observação, entrevista, grupo focal/discussão, questionário, análise documental. Considero importante que os alunos não apenas examinem exemplos de roteiros, mas também façam pequenos ensaios de elaboração de instrumentos de coleta de dados.

7) Análise de Dados - pequenos exercícios de análise de dados quantitativos e qualitativos. Os pós-graduandos precisam aprender a tratar tanto de dados do tipo censitários, como os de caracterização dos sujeitos, quanto as respostas de questões fechadas, assim como aprender a analisar o conteúdo de entrevistas, relatos de observação, de documentos.

Essa é a estrutura que considero ideal para desenvolver um curso semestral de metodologia da pesquisa. Os tópicos são fundamentais para que os pós-graduandos possam elaborar seus projetos e posteriormente desenvolve-los. Evidentemente, uma disciplina não é suficiente para formar o pesquisador prático. O curso deve ser organizado em torno de uma estrutura curricular composta por atividades complementares que vão dar continuidade aos primeiros passos da formação para a pesquisa, assim como suporte teórico metodológico para o desenvolvimento dos projetos.

\section{A pesquisa dos práticos é diferente da pesquisa acadêmica?}

Para concluir, voltamos à questão inicial: em que medida a pesquisa dos práticos se aproxima ou se distancia da pesquisa acadêmica? 
Podemos afirmar agora, que em alguns pontos são similares e em outros, diferentes. Como já antecipávamos em nossa hipótese inicial, posteriormente corroborada por Gatti (2014), as pesquisas acadêmicas têm (ou deveriam ter) um compromisso com a teoria, com o avanço teórico, enquanto a pesquisa "engajada" está voltada para a prática e seu aprimoramento. Assim, elas se diferenciam em termos do objeto.

Ambas se aproximam, no entanto, no sentido em que exigem um caminho rigoroso, ou seja, cuidados metodológicos que qualquer tipo de pesquisa requer. Espera-se do pesquisador: a) que mantenha um nível de controle da situação, o que vai exigir planejamento, tanto dos fins a atingir quanto dos procedimentos para alcançá-los; b) sistematização do conhecimento, ou seja, registro claro e completo dos passos seguidos e das informações obtidas; c) apoio em referenciais e conhecimentos disponíveis, pois, como diz Kaufmann (2011, p. 63), não se pode ignorar o conhecimento já produzido.

Parece não haver dúvida que toda pesquisa envolve muita leitura, o delineamento de um caminho rigoroso e um processo sistemático de planejamento, desenvolvimento e relato dos dados.

Com objetos bem diferenciados, as pesquisas acadêmicas e "engajadas" podem ter procedimentos e metodologias que melhor se adequem a seus diferentes propósitos. Por exemplo, os vários tipos de intervenção-ação parecem responder muito bem aos propósitos de mudança da prática, quando seguem a espiral clássica da pesquisa ação: diagnóstico da situação, implantação de um plano de ação, análise dos resultados, revisão e nova intervenção.

Na perspectiva de John Elliot (2009) a pesquisa ação educacional envolve, por parte dos professores a realização de mudanças educacionalmente valiosas em suas salas de aula ou em outros ambientes de aprendizagem. Ele defende a integração ensino/pesquisa na educação básica e argumenta que não se trata apenas da reflexão crítica sobre o ensinar, mas também de trazer a público, sob alguma forma acessível, as descobertas resultantes da reflexão. 
Defensor das ideias de Stenhouse, Elliot tenta responder às críticas muitas vezes feitas por docentes da universidade quanto a falta de cientificidade da pesquisa-ação e procura esclarecer em seus textos, a história, os fundamentos e os princípios que orientam essa perspectiva (ELLIOT, 2009).

Parece muito adequada a proposição de Elliot, de que não basta desenvolver um processo de reflexão crítica sobre a prática, mas é preciso registrar esse processo, o que vai exigir uma lógica de apresentação, com argumentos e fundamentos, necessários para o relato do estudo e para sua posterior publicização, quando só então poderá ser validado, ou não.

Para concluir, pode-se ficar com a impressão de que o pesquisador prático teria como única escolha a pesquisa-ação já que essa se mostra muito adequada para a implementação de mudanças na prática. No entanto, o interesse do prático pode ser outro, como por exemplo: fazer um estudo documental da política que rege seu trabalho; conhecer práticas formativas inovadoras, que possam inspirar suas ações; conhecer e analisar princípios que fundamentam certas práticas para decidir se deve incorporá-las às suas práticas, ou não; desenvolver e testar uma sequência didática. Alternativas possíveis, viáveis, relevantes.

Assim, não se pode decidir que ao prático fica reservada uma única forma de pesquisa. O que tentamos defender aqui é que a pesquisa-ação é uma modalidade de pesquisa muito apropriada quando o intento for o conhecimento de uma prática situada, com interesse de mudá-la, o que vai demandar do pesquisador, envolvimento em um processo sistemático de estudo, de reflexão e de propostas para seu aprimoramento, com registros dos dados da situação e relato dos resultados obtidos, tornando-os públicos. Porém, há ainda outras possibilidades, igualmente relevantes, para conhecer melhor o próprio trabalho e/ou para descobrir caminhos de como aperfeiçoá-lo.

A conclusão é que tanto a pesquisa acadêmica quanto a "engajada" exigem planejamento, controle e sistematização, pois sem rigor teórico-metodológico não há pesquisa. 


\section{Referências}

ANDRÉ, M. Pesquisa, formação e prática docente. In: ANDRÈ, M. (Org.) O papel da pesquisa na formação e na prática dos professores. Campinas: Papirus, 2012. p. 55-69.

BRASIL. Ministério da Educação. Coordenação de Aperfeiçoamento de Pessoal do Ensino Superior. Portaria n. 080, de 16 de dezembro de 1998. Dispõe sobre o reconhecimento dos mestrados profissionais e dá outras providências. Diário Oficial da União, DF, 11 jan. 1999, Seção I, p. 14; Disponível em: <https://www. capes.gov.br/images/stories/download/avaliacao/avaliacao-n/1892015-Portaria-CAPES-080-1998.pdf>. Acesso em: 15 set. 2016.

ELLIOT, J. What is action research in schools? Journal of Curriculum Studies, $\mathrm{n}$. 10, p. 355-357, 1978.

ELLIOT, J. Research-Based Teaching. In: GEWITZ, S; MAHONEY, P; HEXTALL, I; CRIBB, A. (Eds). Changing Teacher Professionalism: international trends, challenges and ways forward. London and New York: Routledge, 2009. p 170-183.

GATTI, B. A. A Pesquisa em Mestrados Profissionais. In: FOMPE - Fórum de Mestrados Profissionais em Educação, I., 2014, Salvador. Trabalhos apresentados... Salvador: UNEB, mar. 2014.

IMBERNÓN, F. Formação docente e profissional: formar-se para a mudança e a incerteza. São Paulo: Cortez, 2002.

KAUFMANN, J. C. A entrevista compreensiva: um guia para pesquisa de campo. Petropólis: Vozes/Edufal, 2011.

LERNER, D. Investigação em formação: um trabalho compartilhado. Palestra realizada na EFAP - Escola de Formação de Professores d SEESP, 29/09/2012.

LÜDKE, M. O professor e a pesquisa. Campinas, SP: Papirus, 2001.

SAVIANI, D. Do senso comum à consciência filosófica. Campinas: Ed. Cortez e Autores Associados, 2009. 
RIBEIRO, R. J. O mestrado profissional na política atual da Capes. RBPG, Brasília, v. 2, n. 4, p. 8-15, 2005.

RIBEIRO, R. J. Ainda sobre o mestrado profissional. RBPG, Brasília, v. 2, n. 6, p. 313-315, 2006.

STENHOUSE, L. The humanities project. Journal of Curriculum Studies, n. 1, p. 26-33, 1968.

TRIPP, D. Pesquisa-ação: uma introdução metodológica. Educação e Pesquisa, v. 31, n. 3, p. 443-466, 2005.

ZEICHNER, K. Action research in teacher education as a force for greater social justice. Texto a ser publicado, s/d.

Recebido: 01/08/2016

Received: 08/01/2016

Aprovado: 30/08/2016

Approved: 08/30/2016 
